\title{
Textured Breast Implants and Anaplastic Large Cell Lymphoma
}

\author{
CRISTINA-NICO LETA COZMA1,2, ADELAIDA AVINO ${ }^{1 *}$, ANDRA-ELENA BALCANGIU-STROESCU 3,4, DANIELA GABRIELA BALAN ${ }^{3}$, \\ MARIA-DANIELA TANASESCU ${ }^{5,6}$, DELIA TIMOFTE ${ }^{4,7}$, DIANA RUXANDRA SINESCU ${ }^{2,8}$, SILVIA MARIA STOICESCU ${ }^{9}$, \\ DORIN IONESCU5,6 \\ ${ }^{1}$ Prof.Dr.Agrippa Ionescu Clinical Emergency Hospital, Department of Plastic and Reconstructive Surgery, 7 Arh Ion Mincu Str., \\ 011356, Bucharest, Romania \\ ${ }^{2}$ Carol Davila University of Medicine and Pharmacy, Faculty of Medicine, Discipline of Plastic and Reconstructive Surgery, 37 \\ Dionisie Lupu Str., 020021, Bucharest, Romania \\ ${ }^{3}$ Carol Davila University of Medicine and Pharmacy, Faculty of Dental Medicine, Discipline of Physiology, 37 Dionisie Lupu Str., \\ 020021., Bucharest, Romania \\ "Emergency University Hospital Bucharest, Department of Dialysis, 169 Spaiul Independentei, 050098, Bucharest, Romania \\ ${ }^{5}$ Carol Davila University of Medicine and Pharmacy, Faculty of Medicine, Department of Medical Semiology, Discipline of \\ Internal Medicine I and Nephrology, 37 Dionisie Lupu Str., 020021, Bucharest, Romania \\ ${ }^{6}$ Emergency University Hospital Bucharest, Department of Nephrology, 169 Splaiul Independenei, 050098, Bucharest, Romania \\ 'Dialysis Center Sema Parc Bucharest, 319 Splaiul Independenei, 060044, Bucharest, Romania \\ ${ }^{8}$ Elias Clinical Emergency Hospital, Department of Plastic and Reconstructive Surgery, Bucharest, 17 Marasti Blvd., 011461, \\ Bucharest, Romania \\ ${ }^{9}$ Carol Davila University of Medicine and Pharmacy, Faculty of General Medicine, Discipline of Obstetrics-Gynecology, 38-52 Gh. \\ Polizu Str., 011062, Bucharest, Romania

\begin{abstract}
Breast implants are nowadays used in breast augmentation and reconstruction. These can have a silicone or saline filling and a textured or smooth surface. Textured implants have been more frequently used due to their capacity of impairing moving and developing capsular contracture. Breast associated anaplastic large cell lymphoma has been correlated with the presence of textured implants even if the pathogenesis is not entirely understood and other factors might be involved.
\end{abstract}

\section{Keywords: Textured implants, anaplastic large cell lymphoma, silicone}

Breast implants are largely used not only in esthetic breast augmentation, butalso in breast reconstruction after mastectomies and for correcting different congenital breast deformities $[1,2]$. Breast implants have been invented in 1961 by two American plastic surgeons, Thomas Cronin and Frank Gerow, and were first used for a breast augmentation in 1962. These were made of a silicone fill with a shell made of a silicone elastomer [3]. The elastomer was produced by extensive cross-linking of the silicone gel and had a higher consistency [4]. The silicone used for breastimplants is a polymer that contains numerous chains of polydimethyl siloxane monomers which gives stability and flexibility [4]. In 1964, in France, saline implants were invented and were made of a silicone shell and filed with a saline solution [5]. These were used as a second-choice prosthesis due to frequent leakage, having a 2-3\% yearly deflation rate [5].

Besides implant filling, the implant cover became also an issue in implant development. In the beginning, adjacent to the silicone shell a new polyurethane cover of $1.2-2 \mathrm{~mm}$ was realized in order to increase fixation and decrease capsular contracture by realizing an inflammation that decrease formation of a fibrous collagen capsule around the implant [6], but due to its slowly deterioration and risk of implant rupture has been withdrawn from market in 1991 [4]. In order to maintain the benefits of polyurethane coat through decreasing capsular contracture rate but to increase shell strength, textured implants were developed [4].

\section{Breast implant characteristics}

Nowadays, breast implants are divided in the same two categories according to their filling: silicone or saline, their shell being made of silicone elastomer. The surface texture can be textured or smooth and the shape round or anatomic [6].
Silicone breast implants are considered to be gold standard for breast augmentation and reconstruction, having a better breast like consistency than saline implants with less rippling, less malposition and a more natural look [2]. These can be used also in immediate breast reconstruction by using an additional mesh for covering [7], having a great role in decreasing postoperative depression symptoms [8]. The disadvantage might be the necessity of a larger incision, gentle handling by the surgeon and long term evaluation due to risk of rupture and gel migration in the surrounding tissues [4].

The main advantage of saline implant is that it can be inserted in a deflated mode through a small incision after that being filled with saline solution. Also these have a safety profile if rupture happens and are easy to evaluate [4].

Despite the shape and type of breast implants, one of the most important characteristic that have a great involvementin preventing or creating complications is their texture. According to this property, implants can be smooth or textured [6]. Smooth implants have a natural movement, but their disadvantage is the risk of rotation and of forming capsular contracture [8]. Textured implants increase stability and prevent rotation being especially used in anatomic shape (fig. 1). Some studies showed also that have a lower rate of capsular contracture when are placed in a subglandular pocket $[9,10]$, but this difference is not present in all studies [11].

Breast implants are classified nowadays in 4 categories according to their surface roughness macrotexture-puls, macrotexture, microtexture, nanotexture/smooth [12]. Their texturization is realized using a salt-loss technique by adding salt crystal to the silicone and washing creating small pores that adhere to adjacent tissues [6]. There are also other techniques of producing a textured surface like 


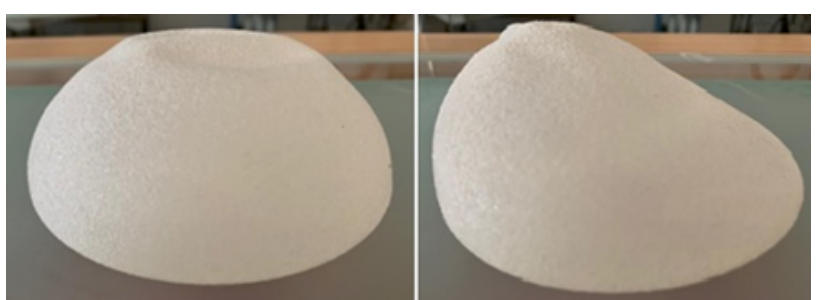

Fig. 1. Textured implants

coating surface with an ammonium carbonate through vulcanization or by pressing silicone mandrel into polyurethane foam that produces pores of $70-1501 \mathrm{~m}$ diameter. The minimal textured models are considered to be nanotextured with a pore dimension of 40-100 $\mu \mathrm{m}$ and are realized through a method of negative imprinting [6].

Textured implants have been used mostly in $85 \%-90 \%$ of the cases in comparison with smooth implants (10-15\%) due to their stability and their lower rate of capsular contracture [12]. These were mostly used for breast reconstruction. Due to a recent discovery (2011) of a delayed complication called breast implant associated anaplastic large cell lymphoma [BIA-ALCL], currently the recommendation is to inform and avoid when possible textured implant in order to lower the possibility of developing this disease [14].

Breast implant associated anaplastic large cell lymphoma Anaplastic large cell lymphoma [ALCL] is a type of a T cell lymphoma, with a rare incidence, that appeared in patients with previous implants [15]. Breast implant associated anaplastic large cell lymphoma is a rare entity, with an incidence of 0.1 to 0.3 per 100000 women with implants, that involves the surrounding breast tissue and is characterized by the presence of a late seroma ( 8 to 10 years after implant surgery) around the implant or the capsule, a tumoral mass or even capsular contracture [16]. Other symptoms may include enlargement of the breast, presence of palpable nodules, pain or inflammation and in some cases even rash and erythema[15]. Primary diagnosis is realized through evaluation of seroma or breast tumoral mass using an ultrasonography that permits aspiration of the fluid or biopsy from the mass. Fluid or tissue analysis is very important and shows a high expression of CD30, a Tcell marker, that is expressed in ALCL. If diagnosis is confirmed, local surgical treatment is required and consists in implants removal with excision of the capsule, surrounding tumoral tissue and suspicious lymph nodes [16]. Surgical treatment is usually sufficient when lymph nodes are not involved. In advanced cases, chemotherapy is usually used and also radiotherapy in locally unresectable tumor [16].

\section{Discussion}

Pathogenesis of ALCL was not entirely discovered, but chronic inflammation might be the promotor of this pathology. There are multiple theories that imply the onset of this local inflammation that include silicone implant leaking, textured implants or the presence of the biofilm [15].

Textured implants have been incriminated in producing ALCL because all the cases diagnosed with this disease had a textured implant. As could have been seen, textured implants are not the main cause, because not all women with textured implants develop ALCL [12]. These could be a trigger or a stimulator in women which have different allergies or genetic predisposition, some women having JAK1/STAT3 gene mutations $[17,18]$.
One of the main problem of textured implants, could be the possibility of peeling of the silicone particles of the implant that could lead to an inflammatory state that increases lymphocyte population [18].

Another characteristic of textured implants is the increased surface that shelters more bacteria than smooth implants ( 72 times more) and stimulates the immune response producing numerous T cell lymphocytes, that could induce development of ALCL [19]. This was sustained also by 2 authors that considered that biofilm is the main factor that triggers the disease and this can be prevented through reducing the intraoperative risk of infection $[20,21]$.

\section{Conclusions}

Breast implant associated anaplastic large cell lymphoma has a multifactorial pathogenesis that implies implant characteristics, microbial factors and host factors like genetic predisposition and immune response. Due to the rare incidence, the epidemiological studies are difficult to be realized in order to understand better its pathogenesis. Recent recommendation is informing any patient about the risk of developing this disease and trying to take any preventing measure as possible.

\section{References}

1.J ECAN C; HERNIC A; FILIP I; RÃDUCU L, J ournal of Mind and Medical Sciences: Vol. 2: Iss. 1,Article 5, [2015]

2.FILIP Cl, JECAN CR, RADUCU L, NEAGU TP, FLORESCU IP. Chirurgia [Bucur]. 2017Jul-Aug;112[4]:378-386.

3.SPEAR SL, PARIKH PM, GOLDSTEIN J A. Clin Plast Surg. 2009 Jan;36[1]:15-21

4.C. R. JECAN et al., Key Engineering Materials, Vol. 638, pp. 197-204, 2015

5.SPEAR SL, JESPERSEN MR. Aesthet Surg J . 2010 J ul-Aug;30[4]:557-70. 6.MEMPIN M, HU H, CHOWDHURY D, DEVA A, VICKERY K. Materials [Basel]. 2018;11[12]:2393. Published 2018 Nov 28.

7.FILIP et. al., Mat. Plast., 54, no. 9, 2017

8.SCAUNASU R V.; VOICULESCU S; POPESCU B; POPA R; BALALAU D; RADUCU L; COZMA, C N.; JECAN C R. Journal of Mind and Medical Sciences: Vol. 5 : Iss. 1 , Article 13, [2018]

9.FARDO D, PENSLER J M. StatPearls [Internet]. Treasure Island [FL]: StatPearls Publishing; 2018 Jan

10.HAKELIUS, L.; OHLSEN, L. Plast. Reconstr. Surg. 1997, 100, 15661569

11.POEPPL N, SCHREML S, LICHTENEGGER F, LENICH A, EISENMANNKLEIN M, PRANTL L. Aesthetic Plast Surg. 2007 Mar-Apr;31[2]:133-9.

12.ATLAN M, NUTI G, WANG H, DECKER S, PERRY T. J Mech Behav Biomed Mater. 2018 Dec;88:377-385.

13.M HAMDI; Aesthetic Surgery Journal, Volume 39, Issue Supplement_1, 31 J anuary 2019, Pages S49-S54

14.***https://www.fda.gov/MedicalDevices/Safety/LetterstoHealth CareProviders/ucm630863.htm

15.SHAHRIARI N, FERENCZI K, HEALD PW. Int J Womens Dermatol. 2017;3[3]:140-144. Published 2017 J ul 11

16. CLEMENS MW, HORWITZ SM.. Aesthet Surg ] . 2017 Mar 1;37[3]:285289.

17.TURNER SD. Aesthet Surg] . 2019] an 31;39[Supplement 1]:S21-S27. 18.DIXON J MICHAEL, CLEMENS MARK. BMJ 2018:363:k5054

19.DASHEVSKY BZ, GALLAGHER KM, GRABENSTETTER A, CORDEIRO PG, DOGAN A, MORRIS EA, HORWITZ SM, SUTTON EJ . reast J. 2019 Jan;25[1]:69-74.

20.HU H, JOHANI K, ALMATROUDI A, ET AL. Plast Reconstr Surg. 2016;137:1659-1669

21.ADAMS WP J R. Plast Reconstr Surg. 2016;137:1670-1672

Manuscript received: 6.12 .2018 